\title{
Analyzing the Status of Korea's Research Funding Institutions and the Characteristics of Funded Projects in the Field of Child Studies
}

\author{
Hui Young Chun \\ Professor, Department of Child Welfare, Kosin University, Busan, Korea \\ 아동학 분야의 연구비 지원 가능 국내 기관 현황과 \\ 연구비 지원 과제의 특성 분석 \\ 천희영 \\ 고신대학교 아동복지학과 교수
}

Objectives: This study aimed to analyze the status of Korea's research funding institutions and the characteristics of funded research projects in the field of child studies.

Methods: Subjects were 440 Korea's research funding institutions registered on the FundRef Registry and 138 projects funded by the National Research Foundation of Korea in the field of child studies, from 2000 to July 2018. Descriptive statistics, frequency analysis, and $t$-test were used for the statistical analysis.

Results: Findings revealed that 126 of the Korean research funding institutions registered on the FundRef Registry ( $28.6 \%$ of the total) supposed to be able to fund research projects on child studies. An analysis of the characteristics of the 138 funded projects on child studies revealed the following findings. Most projects were related to child development, were funded under the Mid-career Researcher Program, and they entailed a 1 year long research. With reference to characteristics of the researchers, it was observed that $52.5 \%$ of the projects were accomplished by researchers funded at once. From all of the funded researchers, funded experience mean was 2.7 as a primary researcher and 0.9 as a joint researcher. Further, mean number of papers published by them was 15.9 and their impact factor mean was 260.3. The most frequent research topic was relational analysis among variables related to social development. Young children and children from multicultural families frequently participated in the projects. The cross-sectional research method and change analysis were used increasingly.

Conclusions: These results suggest the need for information to stimulate researchers to attend funding programs and to increase their research competency.

Keywords: child studies, Korea Research Foundation, FundRef Registry, funded research, research funding institutions

\section{Introduction}

4차 산업혁명 시대를 맞이하여 지식의 전달이나 습득보다는

Corresponding Author: Hui Young Chun, Professor, Department of Child Welfare, Kosin University, 194, Wachiro, Youngdo-gu, Busan, Korea E-mail: chunhy@kosin.ac.kr
지식의 창출 과정이 중요해지고 지식 발전 속도의 가속화에 따른 연구자의 생산적인 연구활동 중요성이 강조되고 있다. 이에 연구자는 연구를 통해 지식을 탐구하고 창출하여 고등교

(C)The Korean Association of Child Studies

This is an Open Access article distributed under the terms of the Creative Commons Attribution Non-Commercial License (http:// creativecommons.org/licenses/by-nc/4.0) which permits unrestricted noncommercial use, distribution, and reproduction in any medium, provided the original work is properly cited. 
육에서 그 지식을 전수하는 연구자로서의 책무를 요구받는다 (Hardre, Beesley, Miller, \& Pace, 2011). 연구활동을 위한 투입의 결과로 얻게 되는 학술적인 산출물을 연구의 생산성이라고 할 때(Woo \& Hong, 2017), 생산적인 연구자는 자기주도적으로 적절한 방법을 적용해 연구를 수행하면서 그 산출물로써 의사 소통을 하는 사람으로서, 학계에서도 인정해 주는 자기책무를 다하는 연구자라 할 수 있다(Harle, Vest, \& Menachemi, 2016).

2010년부터 5년 간 Scopus에는 1,320만 여건에 이르는 많 은 논문이 발표되었고 우리나라 논문의 성장률은 $26.1 \%$ 로 세 계 주요 국가 중 논문발표 실적이 12 위를 차지할 만큼 높게 나 타났다. 이는 세계 주요 국가들이 연구개발 투자비를 지속적 으로 늘여온 결과라 할 수 있다(Elsevier Korea, 2015). 연구비는 연구의 성과와 관련되는 중요 요인으로 국내외 연구에서 밝혀 져 있다. Woo와 Hong (2017)은 행정학 분야에서 연구환경과 연구자의 개인적 특성 변인들 중에서 연구성과에 가장 큰 영 향을 미치는 변인이 연구비의 지원이라고 하였다. 2002년부 터 2010년까지의 다양한 데이터로써 연구비와 연구성과 간의 관계를 연구한 선행연구들(Jang, 2011; Y.-S. Kim \& Jung, 2012; H.-S. Lee et al., 2011)은 연구비가 많을수록 연구생산성이 높 다는 연구(Bolli \& Somogyi, 2011; Brew, Boud, Namgung, Lucas, \& Crawford, 2016; Chen et al., 2015)와 일관된 결과를 보고하 였다. 따라서 우수한 연구성과를 산출하는데 연구비의 지원이 기여하는 바가 크다고 하겠다.

한국연구재단(National Research Foundation of Korea [NRF], 2018a; NRF, 2018d)에 의하면, 2016년 기준 최근 5년간 4년 제 대학의 전임교원이 연구책임자로 수탁하여 지원받은 연 구비는 $14.2 \%$ 증가하였고, 2017년 중앙연구비는 학문분야별 로 연구비 점유율이 공학(46.9\%), 자연과학(19.9\%), 의약학 (18.3\%), 사회과학(5.9\%)의 순으로 높게 나타났다. 그러나 학 문분류 상 자연과학은 13 개 중분류, 135 개 소분류를 포함하 며, 아동학은 그 소분류 중 하나이므로 아동학에서 수혜한 연 구비는 상대적으로 적을 것으로 추측되었다. 같은 보고서에 서 연구비의 재원은 중앙정부 $74.9 \%$, 민간 $14.5 \%$, 교내 $6.5 \%$ 라고 보고되었다. 이에 아동학 분야의 연구자들이 정부연구비 외에 연구비를 지원받을 수 있는 어떤 기관이 있는지 살펴보 는 것은 아동학 분야의 연구과제 수탁 신청을 보다 활성화하 여 연구성과를 높이는 데 도움이 될 것으로 기대되었다.

연구비 지원과 관련된 주체인 지원기관과 수혜 연구 자들 모두는 그 성과물을 효과적으로 관리하고 추적하도 록 요구받는다(Crossref, 2018). 연구비를 지원받고 그 성과 물로 인정받으려면 연구비 지원기관의 정보를 사사 문구 (acknowledgement)로 표기하여야 한다. 연구비 지원기관은 연구비를 수혜 받은 연구자가 어떤 연구성과를 냈는지, 학술 지 발행인은 게재 논문에 대한 연구비 지원기관을 분석할 수 있으며, 정부에서는 연구비 성과물을 투명하게 알릴 수 있다 (Huh, 2014). 그러나 학술지나 출판사 간에 연구비 지원기관 의 표기가 달라서 연구성과나 결과물의 추적이 어렵다는 문제 가 제기되자 2013년부터 Crossref의 주도 하에 연구비 지원기 관 이름의 표준화를 위한 FundRef 즉, 지원기관명 식별 서비 스(funder identification service)가 시작되었다. FundRef는 연구 비 지원기관의 이름을 식별할 수 있도록 일관된 표기 (authority control)를 통해 만들어진 목록(record)인 FundRef Registry를 제 공한다(Crossref, 2018). FundRef Registry를 통해 기관명(funder name), 기관의 공식 다른 명칭(alternate name), 고유번호(funder ID), 기관유형(FundRef body type), 그리고 국가 지명 (geoname) 정보를 알 수 있다. 2014년 6월 기준 FundRef Registry에 등록 된 연구비 지원기관 7,333개 중에는 재단(33.4\%), 대학 및 학 술기관(14.0\%)의 순으로 많지만, 전체의 $5.06 \%$ 에 해당하는 한국의 371 개 기관 중에는 대학 및 학술기관으로 분류된 기 관이 $54.45 \%$, 재단 $1.35 \%$ 로 차이가 있다고 보고되었다(M.-K. Kim, 2015).

현재 우리나라의 전 학문분야의 연구자들을 지원하는 프로 그램으로써 연구역량을 키우는 데 기여하는 대표적인 연구지 원 및 관리 전문기관은 2009년 출범한 NRF이다. NRF (2018b) 는 정부연구비를 위탁 집행하는 준정부기관으로서, 학술 및 연구개발 활동, 그리고 관련 인력의 양성과 활용을 통해 국가 의 학술과 연구역량 제고를 설립 목적으로 한다. 그러므로 아 동학 분야의 연구자들이 연구비 지원을 받을 수 있는 대학 외 대표 기관은 NRF이며, 생활과학에 속하는 연구분야로서 연구 과제 지원을 받고 있다. 그러나 아동학 연구분야에서 연구비 를 지원받은 과제의 선정 현황이나 수행 현황에 대한 분석 연 구는 발표되지 않고 있다.

FundRef에 관한 선행연구로는 그 서비스를 소개하거나 중요성을 강조하는 선행연구들이 대부분이며(Huh, 2014; Meddings, 2013), FundRef Registry에 등록된 연구비 지원기관 명과 국내 의학학술논문에 표기된 연구비 지원기관명을 비 교하여 표기 유형의 차이를 분석한 M.-K. Kim (2015)의 연구 가 발견되었다. 또한 연구자들의 연구성과를 자극하는 연구 비의 지원에 대한 국내 연구들은 행정학 분야에서 다수 발표 되었고(C. Lee, 2010; Woo \& Hong, 2017), 그 연구의 주제들 은 NRF에서 연구비를 수혜한 연구를 포함하여 연구비 지원 과 연구 생산성의 관계에 초점을 두어왔다(Han, Jang, Han, \& 
Yang, 2008; Y.-S. Kim \& Jung, 2012; H.-S. Lee et al., 2011). 따라 서 NRF로부터 연구비를 지원받은 아동학 분야의 연구과제 선 정 및 수행 현황이나 특히, 연구비 지원 과제의 특성이 어떠한 지에 대한 연구가 전무한 상태에 있다고 볼 수 있다.

연구비 지원기관에서 지원 대상자를 선정하거나 교육부의 재정지원사업을 비롯해 연구비 지원 규모를 결정할 때 가장 중요하게 반영하는 것이 연구성과이며, 그 반영 비율이 높아 지는 추세를 보인다(Shin, Kim, Park, \& Shim, 2009). 연구성과 가 부족하면 연구비의 수혜가 어렵고, 연구비의 수혜가 어려우 면 연구 수행이 어려워 연구성과가 부족하게 되는 연구비의 부 익부 빈익빈 현상이 심화될 것으로 예측되었다(H.-S. Lee et al., 2011). 이에 연구비를 지원받은 과제의 특성을 보여주는 대표 적인 지표는 과제수행을 책임진 책임연구자의 역량과 관계된 연구비 수혜실적, 연구업적이라고 할 수 있다. 또한 연구자가 소속된 기관의 소재지에 따라 연구비의 지원 규모에 차이가 있 다고 알려져 있다(Y.-S. Kim \& Jung, 2012). NRF (2018a)는 2016 년 4년제 대학 전임교원 중 수도권 대학에 소속한 연구자의 정 부연구비 수주 금액이 많다고 보고하기도 했다. 덧붙여, NRF 에서 연구비 지원과제를 선정하기 위한 평가에서 높은 비중을 차지하는 평가항목은 연구의 창의성으로, 연구주제의 창의성 과 연구방법의 적절성 및 도전성이 평가지표로 활용된다(NRF, 2018c). 따라서 아동학 분야에서 선정된 연구과제의 연구주제 와 연구방법의 다양한 측면을 분석하는 것은 추후 과제 신청을 위한 유용한 정보를 제공할 것으로 생각되었다.

이같은 배경에서 본 연구는 한국연구재단이 분류한 연구 분야 중 하나인 아동학 분야의 연구를 지원할 가능성이 있는 국내 연구비 지원기관들이 얼마나 되는지의 현황을 FundRef Registry에 등록된 기관 목록을 조사하여 살펴보고, 국내 대표 적인 연구비 지원기관인 NRF에서 연구비를 지원한 아동학 분 야의 연구과제 특성을 분석하는 데 연구의 목적을 두었다. 그 럼으로써 아동학 연구자들의 추후 연구비 지원사업에의 지원 을 자극하고 이를 통해 질 높은 아동학 분야 연구의 성과를 축 적해 나가는 데 도움이 되는 정보를 제공하고자 하였다. 이에 다음의 연구문제를 설정하였다.

\section{연구문제 1}

FundRef Registry 등록 기관 중 아동학 분야 연구비 지원 가 능 국내 기관의 현황은 어떠한가?

\section{연구문제 2}

NRF 아동학 분야의 연구비 지원 과제의 특성은 어떠한가?
2-1. 아동학 분야의 연구비 지원 과제의 선정 및 수행 현황 은 어떠한가?

2-2. 아동학 분야의 연구비 지원 과제의 연구자 특성은 어 떠한가?

2-3. 아동학 분야의 연구비 지원 과제의 연구방법 특성은 어떠한가?

\section{Methods}

\section{분석대상}

연구문제 1의 분석대상은 2018년 3월 12일 현재 FunRef Registry (http://www.crossref.org)에 등록되어 있는 전 세계의 연 구비 지원기관 중 한국의 연구비 지원 기관 440 개였다. 이들 은 등록 파일에서 기관의 국가 지명(geoname)인 'South Korea', 즉 http://sws.geonames.org/18358841 (GeoNames, 2018)로 추 출한 444개 기관 중에서 폐교된 4 개 대학을 제외한 것이었다. Figure 1 에는 기관의 공식 다른 명칭을 제외한 기관 정보를 중 심으로 추출과정을 제시하였다.

연구문제 2의 분석대상은 2018년 7월 31일 현재 NRF가 아동학 분야에서 연구비를 지급한 과제로 검색된 138건이었 다. 이들은 NRF 기초학문자료센터(Korean Research Memory [KRM])의 '연구과제'로 들어가 '연구분야분류별검색' 메뉴에 서 검색기간을 ‘전체'로 설정하였을 때 2000년부터 조사일까 지 등록되어 있는 과제들이었다. 연구분야 분류체계에 따라 대분류 '자연과학'에서 중분류 '생활과학'으로, 다시 소분류 ‘아동학'으로 세부 분류된 것이었다.

\section{분석방법}

본 연구의 조사일 현재 가장 최근인 2018년 3월 7일 FundRef Registry의 연구비 지원기관 등록 리스트 폴더(open-funderregistry-1.16)를 다운받아 분석하였다. 기관들은 FundRef 자체 의 기관 유형 분류에 따라 국가기관과 민간기관으로 대분류되 고, 다시 국가기관은 정부/국가기관과 비정부 국가기관으로, 민간기관은 기업, 대학, 전문가 협회와 단체, 기타 비영리기관, 재단으로 재분류되어 있다.

그러나 국내 FundRef Registry 등록 기관들의 아동학 분야 


\begin{tabular}{|c|c|c|c|c|}
\hline Funder ID & Funder name & Country & Funding body & Subtype \\
\hline http://dx.doi.org/10.13039/100000001 & National Science Foundation & http://sws.geonames.org/6252001 & Government & National government \\
\hline http://dx.doi.org/10.13039/100000002 & National Institutes of Health & http://sws.geonames.org/6252001 & Government & National government \\
\hline http://dx.doi.org/10.13039/100000016 & U.S Department of Health and Human Services & http://sws.geonames.org/6252001 & Government & National government \\
\hline http://dx.doi.org/10.13039/100000019 & National Hemophilia Foundation & http://sws.geonames.org/6252001 & Private organization & corporate \\
\hline http://dx.doi.org/10.13039/100000025 & National Institute of Mental Health & http://sws.geonames.org/6252001 & Government & National government \\
\hline http://dx.doi.org/10.13039/100000026 & National institute on Drug Abuse & http://sws.geonames.org/6252001 & Government & National government \\
\hline http://dx.doi.org/10.13039/100000027 & National Institute on Alcohol Abuse and Alcoholism & http://sws.geonames.org/6252001 & Government & National government \\
\hline http://dx.doi.org/10.13039/100000028 & Semiconductor Research Corporation & http://sws.geonames.org/6252001 & Private organization & corporate \\
\hline http://dx.doi.org/10.13039/100000030 & Centers for Disease Control and Prevention & http://sws.geonames.org/6252001 & Government & National government \\
\hline
\end{tabular}

List of funding institutions registered in FundRef Registry

$\downarrow$

\begin{tabular}{|c|c|c|c|}
\hline Funder ID & Funder name & Funding body & Subtype \\
\hline http://dx.doi.org/10.13039/100004358 & Samsung & Private organization & corporate \\
\hline http://dx.doi.org/10.13039/100007687 & Korean Diabetes Association & Private organization & Professional associations and societies \\
\hline http://dx.doi.org/10.13039/100007775 & Ministry of Construction and Transportation & Government & Federal/national government \\
\hline http://dx.doi.org/10.13039/100007840 & Bioland & Private organization & corporate \\
\hline http://dx.doi.org/10.13039/100008256 & Hyundai Motor Group & Private organization & corporate \\
\hline http://dx.doi.org/10.13039/100008377 & Handok & Private organization & corporate \\
\hline http://dx.doi.org/10.13039/100008378 & Handok Pharmaceuticals & Private organization & corporate \\
\hline http://dx.doi.org/10.13039/100008905 & National Academy of Agricultural Science & Government & Federal/national government \\
\hline
\end{tabular}

List of 444 domestic research funding institutions extracted using the national code (http://sws.geonames.org/18358841)

Figure 1. Process of extracting research funding institutions in Korea.

연구비 지원에 관한 실증적인 분석 자료가 없으므로, 본 연구 에서는 아동학 분야의 연구에 대한 지원 가능성이 없거나 매 우 낮다고 판단되는 기관을 배제한 기관을 '연구비 지원 가능 기관’으로 간주하였다. 구체적으로는 다음과 같은 분석기준을 적용하였다.

첫째, 기관 유형에 관계없이 기관명을 통해 이공계, 의학계 및 산업체 기관인 경우, 대학의 경우 아동(청소년 포함) 관련 학과 즉, 학과명에 ‘아동', ‘청소년’이 포함되어 있거나 유아교 육 전공이 가능한 학과가 없는 대학을 배제하였다. 둘째, 정부 기관 행정부처의 경우, 아동학 분야와 보다 직접적으로 관련 된 기관만을 포함하였다. 예를 들어, 통일부의 경우, 탈북민가 정의 아동 관련 연구에 연구비를 지원할 가능성이 있으나 고 유의 기관 목적에 비추어 제외하였다. 셋째, 정부기관이나 민 간기관의 재단인 경우, 기관명만으로는 연구비 지원 가능성에 대한 판단이 어려운 경우, 해당기관의 홈페이지에서 설립목 적, 사업소개나 사업실적 등을 확인하여 아동학 분야에의 연 구비 지원 가능성을 판단하였다.

연구문제 2, 즉 NRF에서 연구비를 지원한 아동학 분야의 연구과제 특성 분석은 Table 1 에 제시된 분석범주에 따라 이루 어졌다. 첫째, 연구과제의 선정 및 수행 현황 분석을 위해서는 $\mathrm{KRM}$ 의 연구분야분류별검색을 통해 아동학을 포함한 생활과 학의 10 개 연구분야별로 연구비를 지원한 연구과제의 건수를
조사하고, 4개의 연도범주(1차년도 2000년 2004년, 2차년도 2005년 2009년, 3차년도 2010년 2014년, 4차년도 2015년 2018년 7월)별로 아동학의 하위 연구분야별 지원 연구과제 의 건수를 조사하였다. 그리고 연구비 지원 사업별 선정 건수, 연구기간별 건수, 그리고 연구과제의 수행 현황에 해당하는 미종료 여부와 연구결과물의 건수를 $\mathrm{KRM}$ 의 연구분야분류별 검색>자연과학>생활과학>아동학에 제시된 138 개 연구결과 의 리스트에 근거하여 4 개 연도범주별로 조사하였다. 연구결 과물의 경우, 보고서, 논문, 저서별로 4 개 연도범주의 평균 건 수를 산출하였다.

둘째, 연구비 지원 과제의 연구자 특성을 분석하기 위해서 는 NRF에서 2004년부터 2017년까지를 기준으로 제시한(Korea Citation Index [KCI], 2018) 연구비 수혜 업적, 연구 업적, 소 속기관 소재지의 분포를 4 개 범주의 연도별로 분석하였다.

셋째, 연구비 지원 과제의 연구방법 특성은 연구주제, 연구 변인, 연구대상, 발달연구 접근법, 연구방법 유형, 통계분석 방 법 측면에서 하위범주별·4개 연도범주별 분포를 살펴봄으로 써 분석되었다. 이를 위해 연구과제 리스트의 연구과제(재단 과제)별로 링크된 '연구과제 상세정보'에 제시된 연구책임자 정보를 조사하고 과제 신청 시 연구개요, 결과보고서 연구요 약문, 연구결과보고서의 내용을 종합하여 분석범주에 따라 분 석하였다. 연구결과보고서와 연구개요에서 상이한 내용이 발 
Table 1

Analysis Categories to Examine the Characteristics of Research Funding Projects

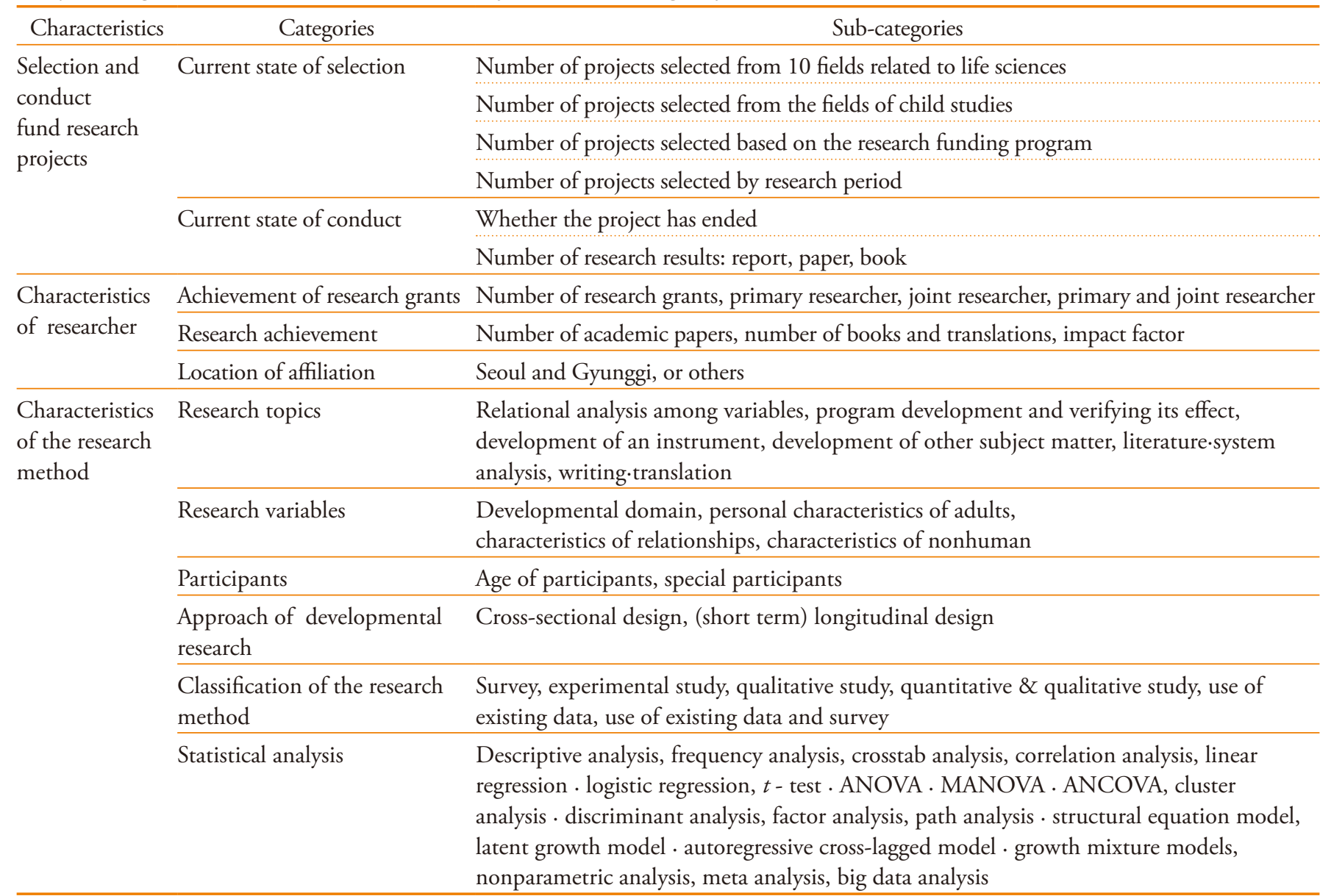

견된 경우, 즉 연구계획과 실제 연구 수행에 차이가 있는 경우 는 연구비 지원 과제 선정 시의 연구계획 내용을 근거로 분석 하였다. 구체적으로 연구변인의 경우, 연구문제와 핵심어를 중심으로 추출하였다. 아동의 인지, 사회, 정서, 언어, 신체 발 달영역, 부모, 교사 등 연구대상에 포함된 성인의 개인적 특성, 아동과 성인 간의 관계적 특성에 해당하는 변인들로 범주화 되었다. 이 외에 어린이집 CCTV 영상과 같은 변인은 비인간 적 특성으로 분류하였다.

\section{연구절차}

연구비 지원 가능 기관과 연구비 지원 과제의 분석자료는 앞 서 밝힌 각 조사일 기준 2-3일 내에 각 사이트로부터 추출되었 다. FundRef Registry의 등록파일은 연구자가 설정한 분석기준 에 따라 연구비 지원 가능 기관 여부에 대해 본 연구자와 아동 학전공 박사학위 소지자 1 인이 함께 평가하였다. 또한 138 개
연구과제의 연구자 및 연구방법 특성의 분석 일치도를 높이기 위해 모든 연구과제의 상세정보를 근거로 같은 2 인이 각자 분 석해 온 결과에 대해 불일치하는 경우 협의하여 분석하였다.

\section{자료분석}

연구문제 1 과 연구문제 2 의 해결을 위해서는 분석범주별로 4 개 연도범주(1차년도 4차년도)에 따른 빈도분석을 하였다. 또한 연구과제의 수행 현황 중 연구결과물, 연구자 특성의 연 구비 수혜 업적과 연구 업적의 경우는 4 개 연도범주별로 평균 과 표준편차, 최댓값과 최솟값을 산출하였다. 부수적으로, 연 구비 수혜 횟수와 연구자 특성 간의 구체적인 관계를 알기 위 해 수혜 횟수를 1 회와 2 회 이상인 두 집단으로 구분하고 $t$ 검증 하였다. 


\section{Results}

\section{FundRef Registry에 등록된 아동학 분야 연 구비 지원 가능 국내 기관의 현황}

FundRef Registry에 등록된 기관 중 아동학 분야 연구비 지원 가능 국내 기관의 현황을 알기 위해, 기관의 유형별 빈도와 유 형 내에서 아동학 분야 연구비 지원 가능 기관의 빈도를 산출 한 결과는 Table 2 와 같다.

Table 2 에서 보듯이, 국내 등록기관 440 개는 국가기관 $39.3 \%$, 민간기관 $60.7 \%$ 로 구성되어 있었다. 국가기관 중 정 부/국가기관은 정부 행정조직에 의한 기관들로서 6 개 기관을 제외하고는 아동학 분야와 직접 관련성이 적은 기관들로서 연 구비 지원 가능성이 매우 낮게 판단되었고 비정부 국가기관 은 모두 병원인 것으로 나타났다. 민간기관 중 기업과 기타 비 영리 기관은 산업체와 병원기관으로 구성되었으며 전문가 협 회와 단체는 생명공학 분야의 기관들이었다. 이에, 대학 중 아 동학 관련 학과가 없는 90 개 대학, 재단의 사업 성격상 아동학 분야의 연구비 지원 가능성이 매우 낮다고 생각되는 8 개 기관 들과 함께 이러한 기관들을 연구비 지원 가능 기관에서 제외 하였다.

따라서 정부/국가기관에 속하는 교육부, 보건복지부, 여성 가족부, 한국교육개발원, 한국교육학술정보원, 한국보건복지 인력개발원, 그리고 민간기관의 재단에 속하는 NRF과 경남 대학교 산학협력단, 대학에 아동학 관련 학과가 있는 118 개교 등 총 126 개 기관(28.6\%)을 아동학 분야의 연구비 지원 가능 기관으로 볼 수 있었다.

\section{$\mathrm{NRF}$ 의 아동학 분야 연구비 지원 과제의 특성}

\section{연구과제의 선정 및 수행 현황}

$\mathrm{NRF}$ 에 의한 아동학 분야의 연구비 지원 연구과제의 특성을 알 기 위해, 선정 현황의 한 측면으로서 첫째, 생활과학의 10 개 연 구분야 즉, 아동학, 가족학, 소비자학, 가정자원경영, 영양학, 식 품학, 급식경영학, 의류학, 주거학, 기타생활과학의 분야별 선 정 연구과제의 건수를 살펴보았다. 이에 2000년부터 2018년 7 월 말까지 전체 454 건의 연구과제가 연구비를 받았고, 연구분 야 중에서는 아동학(138건, $30.4 \%$ ), 소비자학(128건, $28.2 \%)$, 가 족학(99건, 21.8\%)의 순으로 많다는 것을 알 수 있었다.

둘째, 전체 조사기간 동안 아동학의 5 개 하위 연구분야별
선정 건수를 빈도분석한 결과, 아동발달이 63건(45.7\%)으로 가장 많고, 청소년학 28건(20.3\%), 아동보육 24건(17.4\%), 아 동상담/치료 16건(11.6\%), 그리고 하위 연구분야가 세분화되 기 전의 아동학이 7 건(5.1\%)로 나타났다. 아동발달은 4 개 연 도범주 모두에서 최다 선정된 분야로 나타났다.

셋째, 연구비 지원사업별 선정 건수를 알기위해 지원사업 별·연도범주별 연구과제의 빈도를 분석하고 그 결과를 Table 3에 제시하였다.

Table 3 에서 알 수 있듯이, 전체 14 가지의 지원사업에서 중 견연구자 지원사업 $29.0 \%$, 신진연구자(및 신진연구장려금) 지원사업 $23.2 \%$, 학문후속세대 지원사업(시간강사 지원사업) $20.3 \%$, 학문후속세대 지원사업(박사후 국내연수, 박사후 해외 연수, 학술연구교수) $8.7 \%$ 의 순으로 지원받은 과제 수가 많은 것으로 나타났다.

넷째, 연구비 지원을 받은 과제의 연구기간은 79.0\%(109 건)가 1 년이었고, 3 년 16 건(11.6\%), 2년 11건(8.0\%)으로 나타 났으며 연구가 중단된 것은 아니지만 5 개월과 6 개월인 경우 가 각 1 건으로 나타났다. 연구기간이 2 년이나 3 년인 경우는 2010년 이후 상대적으로 증가한 것으로 볼 수 있었다.

연구과제의 수행 현황으로서 첫째, 미종료 여부를 살펴본 결과, 138 건의 연구과제 중 132 건은 종료 또는 진행 중이지만 1 차년도 2 건, 2 차년도 1 건, 3 차년도 3 건 등 총 6 건은 중단되었 음을 알 수 있었다. 그 이유가 제시된 경우는 사업별로는 학문 후속세대 지원사업 3 건, 신진연구자장려금 지원사업 1건, 시 간강사 지원사업 1 건, 명저번역 지원사업 1 건이었다. 연구가 중단된 이유가 제시된 2건의 경우 취업으로 인한 중단으로 밝 혀져 있었다.

둘째, 연구결과물로써 수행 현황을 살펴본 결과, 보고서 의 경우, 2 차년도 4 건, 3 차년도 2 건이 미제출되어 각 $69.2 \%$, $96.4 \%$ 의 제출율을 보였다. 4 차년도의 연구과제 36 건 중에서 21 건(58.3\%)은 아직 미제출 상태에 있었다. 논문의 경우, 연 구가 종료된 1차, 2차 및 3차년도 시기동안 각 연구과제 당 평 균 1.78편(최소 1편 최대 8편), 1.15편(최소 1편 최대 3편), 1.15 편(최소 1 편 최대 8 편)이 발표된 것으로 나타났다. 저서 는 2003년 일반공동연구 지원사업, 2012년 저서출판 지원사 업에서 각 1편, 그리고 2010년 한국사회과학연구(SSK) 지원사 업에서 2편이 출판된 것으로 나타났다. 
Table 2

Frequency Analysis of Funding Institutions Registered on FundRef Registry and Institutions that may Support Research Fund

\begin{tabular}{|c|c|c|c|}
\hline & Funding body type & Institutions that may fund research & $\begin{array}{c}\text { Frequency } \\
(\%)^{\mathrm{a}}\end{array}$ \\
\hline Government & Federal/national government & $\begin{array}{l}150 \text { (34.1) Ministry of Gender Equality and Family, Ministry of } \\
\text { Health and Welfare, Korean Women's Development } \\
\text { Institute, Korean Educational Development Institute, Korea } \\
\text { Education and Research Information Service, Korea Human } \\
\text { Resource Development Institute for Health and Welfare }\end{array}$ & $6(4.0)$ \\
\hline \multirow{3}{*}{$\begin{array}{l}\text { Private } \\
\text { organization }\end{array}$} & Corporate & $21(4.8)$ & $0(\quad .0)$ \\
\hline & Academic & 208 ( 47.3) Universities having departments related to children & $118(56.7)$ \\
\hline & Professional associations and societies & $7(1.6)$ & $0(\quad .0)$ \\
\hline Total & & $440(100.0)$ & $126(28.6)$ \\
\hline
\end{tabular}

Note. ${ }^{a} \%$ in the same type.

Table 3

Results of the Frequency Analysis of Funded Projects Based on the Research Funding Program and Research Period

\begin{tabular}{|c|c|c|c|c|c|c|}
\hline Category & Programs & $\begin{array}{c}2000 \\
\sim 2004\end{array}$ & $\begin{array}{c}2005 \\
\sim 2009\end{array}$ & $\begin{array}{c}2010 \\
\sim 2014\end{array}$ & $\begin{array}{c}2015 \sim \\
\text { July } 2018\end{array}$ & Total \\
\hline \multirow{3}{*}{$\begin{array}{l}\text { Individual } \\
\text { research }\end{array}$} & Mid-career researcher program & $12(40.0)$ & $2(14.3)$ & $12(20.7)$ & $14(38.9)$ & $40(29.0)$ \\
\hline & $\begin{array}{l}\text { Fostering next-generation } \\
\text { researchers program } \\
\text {-part time university faculty }\end{array}$ & $0(\quad .0)$ & $0(\quad .0)$ & $18(31.0)$ & $10(27.8)$ & $28(20.3)$ \\
\hline & $\begin{array}{l}\text { Fostering next-generation } \\
\text { researchers program } \\
\text {-post-doctoral training in } \\
\text { Korea, post-doctoral training abroad, or the } \\
\text { presidential post-doctoral fellowship }\end{array}$ & $4(13.3)$ & $4(28.6)$ & $3(5.2)$ & $1(2.8)$ & $12(8.7)$ \\
\hline \multirow{3}{*}{$\begin{array}{l}\text { Outcome } \\
\text { dissemination }\end{array}$} & Excellent paper & $0(\quad .0)$ & $1(7.1)$ & $3(5.2)$ & $1(2.8)$ & $3.6)$ \\
\hline & Book publishing & $0(\quad .0)$ & $0(\quad .0)$ & $1(1.7)$ & 0( & 1( \\
\hline & Masterwork translation & $0(\quad .0)$ & $0(\quad .0)$ & $1(1.7)$ & $0(\quad .0)$ & 1( \\
\hline \multirow[t]{3}{*}{ Others } & Lecture for disciplines to be protected & $0(\quad .0)$ & $2(14.3)$ & $0(\quad .0)$ & $0(\quad .0)$ & $2(1.4)$ \\
\hline & Dissemination of advanced knowledge & $0(\quad .0)$ & $1(7.1)$ & $0(\quad .0)$ & $0(\quad .0)$ & $1(\quad .7)$ \\
\hline & Total & $30(100.0)$ & $14(100.0)$ & $58(100.0)$ & $36(100.0)$ & $138(100.0)$ \\
\hline
\end{tabular}




\section{연구과제의 연구자 특성}

연구과제의 연구자 특성으로서 연구비 수혜 업적과 연구 업적 을 분석하기에 앞서 2000년 이후 총 조사기간 동안 4 개 연도 범주별로 연구비 수혜 업적과 연구 업적의 기술통계치와 최댓 값, 최솟값을 살펴본 결과는 Table 4에 제시된 바와 같다.

Table 4에서 알 수 있듯이, 연구비 수혜 업적으로서 정보가 제시된 전체 연구과제 137 건에서 책임연구자 횟수의 평균은 2.7회 $(S D=1.8)$ 였고, 최소 1 회, 최대 7회의 책임연구자 업적이 있는 것으로 나타났다. 또, 3 차년도와 4차년도의 책임연구자 횟수 평균이 그 전 시기보다 상대적으로 높다는 것을 알 수 있
었다. 이에 비해 공동연구자 횟수는 전체 연구과제 137 건 당 평균 0.9 회 $(S D=1.4)$ 로 최소 전무, 최대 7회의 업적이 있는 것 으로 나타났다. 책임연구자와 공동연구자로서의 횟수를 합한 경우, 전체의 평균은 3.7 회 $(S D=2.8)$, 최소 1 회, 최대 14 건으로 나타났다.

연구자의 연구 업적 역시 Table 4에 제시된 바와 같이 전체 137 건에 대해 학술논문게재 편수는 평균 15.9 편 $(S D=16.8)$, 최소 0 편, 최대 112 편으로 나타났고, 3 차년도와 4 차년도의 편 수 평균과 최댓값이 상대적으로 높아진 것을 알 수 있었다. 전 체 137 건 기준 저역서 편수는 0.2 편 $(S D=0.5)$, 최소 0 편, 최대 4 편으로 나타났다. 연구자의 피인용 횟수는 제시되어 있는

Table 4

Characteristics of Research Fund Beneficiaries by Research Period

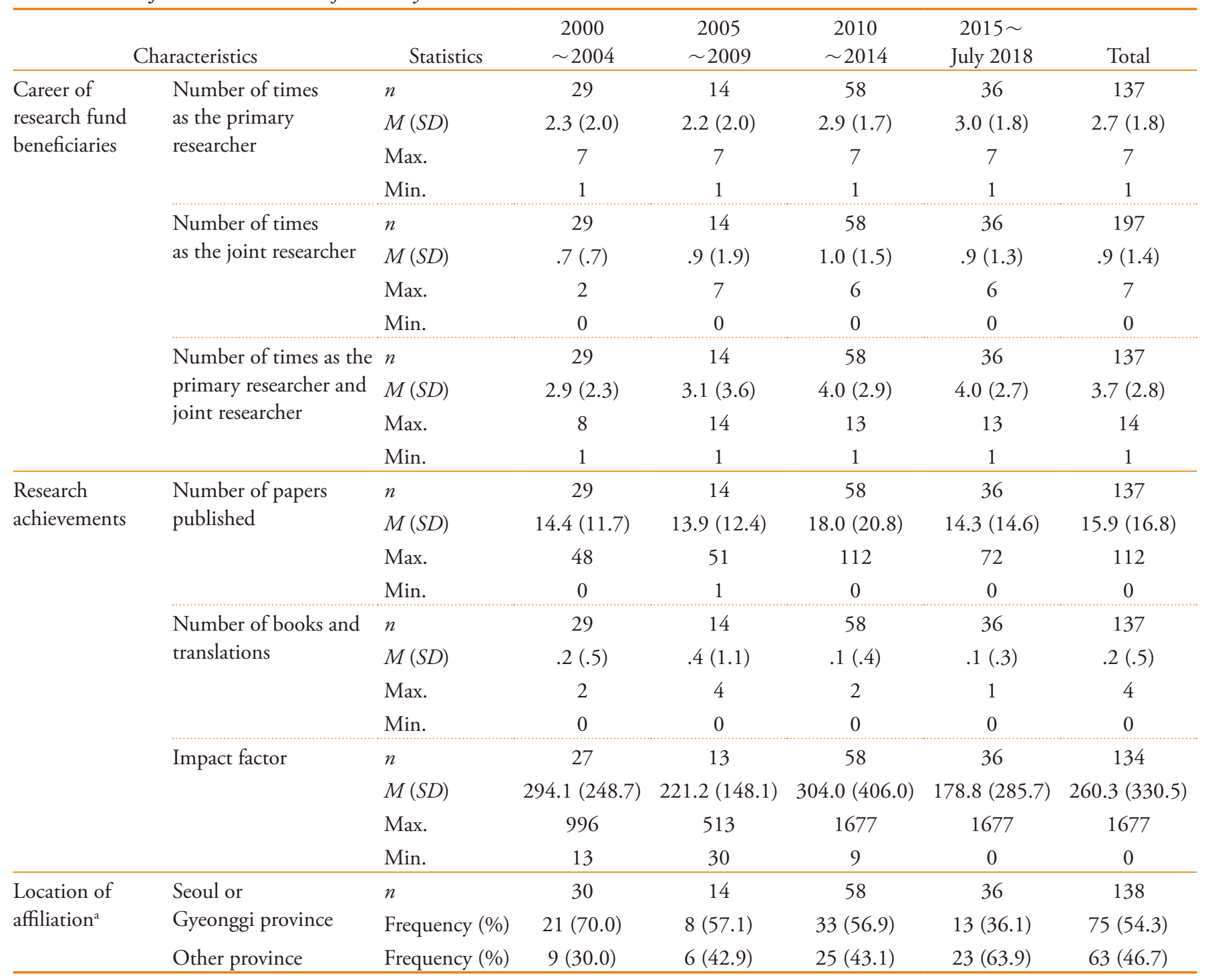

Note. ${ }^{a}$ Characteristics based on total researchers. 
134 건을 기준으로 할 때 평균 260.3 회 $(S D=330.5)$, 최소 0 회, 최대 1677회로 나타났다.

또 연구자의 소속기관 소재지는 전체 138 건 중 서울과 경 기지역의 대학인 경우가 75건(54.3\%), 그 외 지역은 63건 (45.7\%)으로 분포되어 있었다. 서울과 경기 외 지역 대학 소속 의 연구자가 전체 연구기간동안 수혜한 연구과제 수는 증가함 을 알 수 있었다.

한편, 연구자의 연구비 수혜 횟수별 과제선정 건수를 살펴 본 결과, 1 회 수혜자들에 의해 72 건(52.2\%) 선정되었고, 나머 지 68건은 수혜 횟수가 2회인 15명(30건), 3회인 6명(18건), 4 회인 2명(8건), 5 회인 2명(10건)에 의해 각각 선정되었음을 알 수 있었다. 구체적으로 연구비 수혜 횟수와 연구자 특성 간의 관계를 알기 위해 1 회 수혜자 72 명과 2 회 이상 수혜자 25 명의 두 집단 간 차이를 $t$ 검증한 결과, 책임연구자 횟수 $(M=1.68$, $S D=1.12 ; M=3.48, S D=1.66 ; t=-5.04, p<.001)$ 와 책임 및 공동 연구자 횟수 $(M=2.30, S D=1.97 ; M=4.60, S D=2.63 ; t$ $=-4.00, p<.001)$ 에서만 유의한 차이가 있는 것으로 나타났다. 이에 수혜 횟수가 1 회인 연구자보다 2 회 이상인 연구자는 책 임연구자 횟수, 책임 및 공동 연구자 횟수가 유의하게 많다는 것을 알 수 있었다.

\section{연구과제의 연구방법 특성}

연구과제의 연구방법은 연구주제, 연구변인, 연구대상, 발달 연구접근법, 연구방법 유형, 통계분석 방법의 범주로 나뉘어 분석되었다(Table 5).

첫째, 연구주제를 연도범주별로 그 하위범주에 따라 분석 한 결과, 변인간의 관계분석이 85 건(61.6\%), 프로그램의 개발 및 효과가 28건(20.3\%)의 높은 빈도로 나타났다. 그러나 도구 개발과 기타 개발이 차지하는 비율은 1 차년도와 2 차년도에 비해 3차년도와 4차년도에 상대적으로 높아지는 것으로 나타 났다. 연구주제별·연도범주별 연구과제의 예는 Appendix 1에 제시하였다.

둘째, 연구변인의 특성을 아동의 발달영역별로 나누어 다 중빈도분석을 했을 때, 사회성 발달에 속한 연구변인을 다룬 과제가 87건, 정서 발달 39건, 인지발달 21건, 신체발달 11건, 언어발달 8 건의 순으로 해당 변인들이 연구과제에서 다루어 진 것으로 나타났다. 아울러 부모, 교사 등 성인의 개인적 특성 은 48건에서, 관계적 특성은 50건에서 다루어졌으며, 비인간 적 특성은 25건에서 다루어진 것을 알 수 있었다.

셋째, 연구대상의 특성으로서 연구대상의 연령별 분포를
살펴본 결과, 유아 대상의 연구과제가 49건(35.5\%), 초등학 생 대상 32건(23.2\%)으로 상대적인 빈도가 높게 나타났다. 영 아, 영아 및 유아, 중학생 및 고등학생(또는 청소년)은 각 12 건 (8.7\%)으로 나타났다. 유아는 2차년도 이후 계속 상대적으로 최다 연구대상으로 선정되었음을 알 수 있었다.

나아가 특수 연구대상으로써 연구과제의 특성을 분석하고 Table 6에 그 결과를 제시하였다. Table 6에 의하면, 특수 연구 대상을 포함한 연구과제는 총 48건으로 전체 138건 중 34.8\% 를 차지하며, 다문화가정의 아동이 10 건(20.8\%), 발달정신병 리아동이 7건(14.6\%)으로 상대적으로 많이 다루어진 것을 알 수 있었다. 또한 각 연도범주 내에서 총 선정 건수를 기준으로 했을 때 1 차년도와 2 차년도에는 선정과제의 $50.0 \%$ 에서 특수 연구대상이 다루어졌으나, 3 차년도에는 $42.0 \%, 4$ 차년도에는 $26.1 \%$ 로 상대적으로 감소한 것으로 나타났다.

발달연구 접근법·연구방법 유형·통계분석 방법에 따른 연 구과제의 건수를 연도범주별로 분석한 결과는 Table 7에 제시 된 바와 같다.

넷째, Table 7에서 보듯이, 발달연구 접근법이 적용된 연구 과제는 50건으로, 횡단적 접근이 29건(58.0\%), (단기)종단적 접근이 21건(42.0\%)에서 적용되었으며, 특히 후자는 3차년도 와 4 차년도에 16 건이 분포된 것으로 나타났다. (단기)종단연 구의 기간은 1 년이 8 건(38.1\%)으로 가장 많고 2 년과 3 년은 각 5건, 5년은 3건으로 나타났다.

다섯째, 미상으로 검색된 1 건을 제외한 137 건의 연구과제 에 적용된 연구방법 유형은 Table 7에 제시된 바와 같이 조사 연구 84건(61.3\%), 실험연구 21건(15.3\%), 양적 및 질적연구 11 건(8.0\%), 기존에 수집된 데이터를 활용하거나 이에 조사연 구를 추가한 연구가 9 건 $(6.6 \%)$ 선정된 것으로 나타났다. 질적 연구와 문헌연구는 각 6건(4.4\%)인 것으로 나타났다.

여섯째, 연구과제에 적용된 통계분석 방법을 다중빈도분석 한 결과는 Table 7과 같이 $t$ 검증과 변량분석과 같은 평균의 차 이검증이 57건(27.8\%)에서 가장 많이 적용된 것으로 나타났 다. 10 건을 초과하여 적용된 분석방법은 상관분석(37건), 회귀 분석(28건), 경로분석 및 구조방정식모형(27건), 잠재성장모 형·자기회귀교차지연모형·성장혼합모형(13건), 요인분석(12 건)이었다. 특히 후자의 세 범주의 통계분석 방법은 3 차년도 와 4차년도 시기에 그 이전 시기에서보다 상대적으로 적용 빈 도가 높은 것으로 나타났다. 
Table 5

Results of the Frequency Analysis of Funded Projects by Research Topic and Research Period

\begin{tabular}{lccccc}
\hline \multicolumn{1}{c}{ Topic category } & $2000 \sim 2004$ & $2005 \sim 2009$ & $2010 \sim 2014$ & $2015 \sim$ July 2018 & Total \\
\hline Relational analysis among variables & $20(23.5)$ & $6(7.1)$ & $40(47.1)$ & $19(22.4)$ & $85(100.0)$ \\
Program development and its effect & $5(17.9)$ & $6(21.4)$ & $10(35.7)$ & $7(25.0)$ & $28(100.0)$ \\
Development of an instrument & $1(9.1)$ & $2(18.2)$ & $4(36.4)$ & $4(36.4)$ & $11(100.0)$ \\
Development of other subject matter & $2(25.0)$ & $0(.0)$ & $2(25.0)$ & $4(50.0)$ & $8(100.0)$ \\
Literature. system analysis & $2(50.0)$ & $0(.0)$ & $0(.0)$ & $2(50.0)$ & $4(100.0)$ \\
Writing. translation & $0(.0)$ & $0(.0)$ & $2(100.0)$ & $0(0.0)$ & $2(100.0)$ \\
\hline
\end{tabular}

Note. $N=138$.

Table 6

Results of the Frequency Analysis of Special Participants by Research Period

\begin{tabular}{|c|c|c|c|c|c|}
\hline Special participants & $2000 \sim 2004$ & $2005 \sim 2009$ & $2010 \sim 2014$ & 2015 July 2018 & Total \\
\hline Children from multicultural families ${ }^{a}$ & $0(\quad .0)$ & $2(28.6)$ & $5(33.3)$ & $3(27.3)$ & $10(20.8)$ \\
\hline Overseas Korean children, multinational children ${ }^{\mathrm{b}}$ & $2(13.3)$ & $1(14.3)$ & $2(13.3)$ & $0(\quad .0)$ & $5(10.4)$ \\
\hline Abused children (including abusive parents) & $0(\quad .0)$ & $1(14.3)$ & $0(\quad .0)$ & $3(27.3)$ & $4(8.3)$ \\
\hline Victims of peer harassment or cyber harassment & $2(13.3)$ & $0(\quad .0)$ & $0(\quad .0)$ & $1(9.1)$ & $3(6.3)$ \\
\hline Children from special families ${ }^{c}$ & $3(20.0)$ & $0(\quad .0)$ & $1(6.7)$ & $0(\quad .0)$ & $4(8.3)$ \\
\hline Children with developmental psychopathologies ${ }^{d}$ & $1(\quad 6.7)$ & $2(28.6)$ & $3(20.0)$ & $1(9.1)$ & $7(14.6)$ \\
\hline Children from low-income families ${ }^{\mathrm{e}}$ & $1(\quad 6.7)$ & $0(\quad .0)$ & $2(13.3)$ & $1(9.1)$ & $4(8.3)$ \\
\hline Gifted child & $1(\quad 6.7)$ & $0(\quad .0)$ & $0(\quad .0)$ & $0(\quad .0)$ & $1(2.1)$ \\
\hline Obese youth & $0(\quad .0)$ & $0(\quad .0)$ & $1(\quad 6.7)$ & $0(\quad .0)$ & $1(2.1)$ \\
\hline Out-of-home children ${ }^{\mathrm{f}}$ & $2(13.3)$ & $1(14.3)$ & $0(\quad .0)$ & $0(\quad .0)$ & $3(6.3)$ \\
\hline Children from North Korean escape family & $1(\quad 6.7)$ & $0(\quad .0)$ & $0(\quad .0)$ & $0(\quad .0)$ & $1(2.1)$ \\
\hline Literature and resources ${ }^{g}$ & $2(13.3)$ & $0(\quad .0)$ & $1(\quad 6.7)$ & $2(18.2)$ & $5(10.4)$ \\
\hline Total & $\begin{array}{r}15(100.0) \\
\quad(50.0)^{\mathrm{h}}\end{array}$ & $\begin{array}{c}7(100.0) \\
(50.0)^{\mathrm{h}}\end{array}$ & $\begin{array}{r}15(100.0) \\
\quad(42.0)^{\mathrm{h}}\end{array}$ & $\begin{array}{l}11(100.0) \\
\quad(26.1)^{\mathrm{h}}\end{array}$ & $\begin{array}{r}48(100.0) \\
\quad(34.8)^{\mathrm{h}}\end{array}$ \\
\hline
\end{tabular}

Note. ${ }^{a}$ Young children, elementary school children, and youth from a multicultural emotional crisis family, international marriage family, bilingual family, and children from rural small-scale multicultural schools.

${ }^{\mathrm{b}}$ Children returning from overseas, Korean adoptive children living in the US, multinational children (Korean, Chinese, Chinese-

American), Korean American youth living in the US, youth to US for study at a young age, infants (International joint research).

c Children from a divorced family, single-parent family, parental separation family, grandparents-grandchildren family.

${ }^{d}$ Children diagnosed with autism spectrum, children with anxious attachment to the father, children with disabilities in an integrated class (teacher, and one or both parents of children without disabilities), integrated child care facilities for children with disabilities, underachieving children, children with developmental psychopathologies, youth exhibiting suicidal ideation.

${ }^{\mathrm{e}}$ Children from low income homes, and those with Attention Deficit Hyperactivity Disorder.

${ }^{\mathrm{f}}$ Youth in a shelter, facility-protected children (young children).

${ }^{g}$ CCTV image data, baby picture book, literature, historical famous book, newspaper articles.

${ }^{\text {h }}$ Percentage based on total number of projects by year category. 
Table 7

Results of the Frequency Analysis of Developmental Research Design, Classification of the Research Method, and Statistical Analysis Methods

\begin{tabular}{|c|c|c|c|c|c|c|}
\hline & Categories & $\begin{array}{l}2000 \\
\sim 2004\end{array}$ & $\begin{array}{c}2005 \\
\sim 2009\end{array}$ & $\begin{array}{l}2010 \\
\sim 2014\end{array}$ & $\begin{array}{l}2015 \sim \\
\text { July } 2018\end{array}$ & Total \\
\hline \multirow{2}{*}{$\begin{array}{l}\text { Research design } \\
(N=49)\end{array}$} & Cross-sectional design & $8(66.7)$ & $2(66.7)$ & $8(47.1)$ & $11(61.1)$ & $29(58.0)$ \\
\hline & (Short term) longitudinal design & $4(33.3)$ & $1(33.3)$ & $9(52.9)$ & $7(38.9)$ & $21(42.0)$ \\
\hline \multirow{6}{*}{$\begin{array}{l}\text { Classification of } \\
\text { research } \\
\text { method } \\
(N=137)\end{array}$} & Survey & $21(72.4)$ & $8(57.1)$ & $32(55.2)$ & $23(63.9)$ & $84(61.3)$ \\
\hline & Experimental study & $4(13.8)$ & $4(28.6)$ & $8(13.8)$ & $5(13.9)$ & $21(15.3)$ \\
\hline & Qualitative study & $1(3.4)$ & $1(7.1)$ & $1(1.7)$ & $3(8.3)$ & $6(4.4)$ \\
\hline & Quantitative and qualitative study & $1(3.4)$ & $1(7.1)$ & $7(12.1)$ & $2(5.6)$ & $11(8.0)$ \\
\hline & Literature study & $2(6.9)$ & $0(.0)$ & $3(5.2)$ & $1(2.8)$ & $6(4.4)$ \\
\hline & Use of existing data, use of existing data and survey & $0(\quad .0)$ & $0(\quad .0)$ & $7(12.1)$ & $2(5.6)$ & $9(6.6)$ \\
\hline \multirow{13}{*}{$\begin{array}{l}\text { Statistical } \\
\text { analysis }\end{array}$} & Descriptive analysis & $2(3.9)$ & $0(.0)$ & $1(1.2)$ & $1(2.0)$ & $4(2.0)$ \\
\hline & Frequency analysis & $3(5.9)$ & $0(.0)$ & $4(4.8)$ & $3(6.1)$ & $10(4.9)$ \\
\hline & Crosstab analysis & $4(7.8)$ & $0(.0)$ & $1(1.2)$ & $3(6.1)$ & $8(3.9)$ \\
\hline & Correlation analysis & $10(19.6)$ & $3(13.6)$ & $15(18.1)$ & $9(18.4)$ & $37(18.0)$ \\
\hline & Linear regression $\cdot$ logistic regression & $9(17.6)$ & $2(9.1)$ & $12(14.5)$ & $5(10.2)$ & $28(13.7)$ \\
\hline & $t$-test $\cdot$ ANOVA $\cdot$ MANOVA $\cdot$ ANCOVA & $16(31.4)$ & $10(45.5)$ & $22(26.5)$ & $9(18.4)$ & $57(27.8)$ \\
\hline & Cluster analysis $\cdot$ discriminant analysis & $1(2.0)$ & $1(4.5)$ & $1(1.2)$ & $1(2.0)$ & $4(2.0)$ \\
\hline & Factor analysis & $1(2.0)$ & $3(13.6)$ & $4(4.8)$ & $4(8.2)$ & $12(5.9)$ \\
\hline & Path analysis $\cdot$ structural equation model & $4(7.8)$ & $1(4.5)$ & $15(18.1)$ & $7(14.3)$ & $27(13.2)$ \\
\hline & $\begin{array}{l}\text { Latent growth model } \cdot \text { autoregressive cross-lagged } \\
\text { model } \cdot \text { growth mixture models }\end{array}$ & $0(\quad .0)$ & $1(4.5)$ & $7(8.4)$ & $5(10.2)$ & $13(6.3)$ \\
\hline & Nonparametric analysis & $1(2.0)$ & $1(4.5)$ & $0(\quad .0)$ & $0(\quad .0)$ & $2(1.0)$ \\
\hline & Meta analysis & $0(.0)$ & $0(.0)$ & $1(1.2)$ & $1(2.0)$ & $2(1.0)$ \\
\hline & Big data analysis & $0(\quad .0)$ & $0(\quad .0)$ & $0(\quad .0)$ & $1(2.0)$ & $1(.5)$ \\
\hline
\end{tabular}

Note. ${ }^{2}$ Results by multi-frequency analysis.

\section{Discussion}

본 연구는 아동학 분야의 연구를 지원할 가능성이 있는 국내 연구비 지원기관들이 얼마나 되는지를 FundRef Registry에 등 록된 기관 목록을 통해 살펴보고, 국내 대표적인 연구비 지원 기관인 NRF에서 연구비를 지원한 아동학 분야의 연구과제 특 성을 분석하는 데 연구의 목적을 두었다. 연구결과를 요약하 며 논의하면 다음과 같다.

본 연구에서 아동학 분야에 대한 연구비 지원이 가능한 기 관은 그 지원 가능성이 없거나 매우 낮은 기관을 배제한 기 관들로서 FundRef Registry에 등록된 기관 중 총 126개 기관 (28.6\%)이 해당한다고 추정되었다. NRF가 아동학을 포함해 서 전반적인 학문 분야 연구자들의 연구역량을 향상시키는 데 기여하고 있으나(C. Lee, 2010) 연구비 지원기관의 절대 다수 를 차지하는 대학의 연구비 점유율은 중앙정부의 약 11 배 이
상 적다고 보고된 바 있다(NRF, 2018a). 따라서 아동학 분야의 연구자들이 연구비를 지원받을 수 있는 기회가 매우 적을 것 으로 추측할 수 있었다. Son (2013)에 의하면, 미국 연방정부는 연구지원 프로그램을 통해 아동발달 관련 연구를 학문 분야나 주제에 따라 세부적으로 나누어 지원하되, 정기적으로 제시하 는 공모 주제에 연구자들이 관심을 가지고 연구비를 신청하도 록 하고 있다. 그렇지 못한 한국의 상황에서는 정부와 정부 관 련 지원기관의 역할을 보완할 수 있도록 아동과 가족 관련 단 체나, 기관들의 연구비 지원이 필요하다는 지적(Son, 2013)을 기억할 필요가 있었다.

$\mathrm{NRF}$ 에서 연구비를 지원한 아동학 분야의 연구과제 특성 으로서, 먼저 아동학 분야에서 선정된 138 건은 같은 기간 생 활과학의 하위 학문분야들에 비해 선정 비율이 가장 높았고, 아동학의 5 개 연구분야 중에서는 아동발달 분야의 연구과제 가 2000년 이후 지속적으로 최다 선정된 것으로 나타났다. 이 
는 아동학이 아동과 관련된 포괄적인 주제를 다루는 다학문적 성격을 띠고 아동과 환경 간의 상호작용을 탐색하는 데 있어 ‘아동/청소년의 발달'이 대표적인 연구영역이라는 점(Korean Association of Child Studies [KACS], 2018)에서 당연한 결과로 볼 수 있었다.

연구비 지원사업별 선정 건수를 분석한 결과, 중견연구자 지원사업과 학문후속세대 지원사업이 각각 $29 \%$ 선정되었음 을 알 수 있었다. 최근 대학의 아동학과가 없어지면서 아동학 분야의 대학 교원 임용이 줄어듦으로써 신진연구자 지원사업 은 $23.2 \%$ 를 차지하는 것으로 나타났다. 또한 3차년도와 4 차 년도에 신진연구자와 중견연구자의 수혜 건수가 증가한 것은 2012년에서 2017년까지 정액연구 지원이 가능했던 것과 관계 가 있을 것으로 추측해 볼 수 있었다. Aithal (2016), Hollister와 Schroeder (2015)는 대학의 전임연구자는 지위와 경제적 안정 속에서도 내적 학문적 성취동기가 강하고, 학문후속세대와 같 은 비전임연구자는 직위나 보수와 같은 외재적 동기가 강하다 고 보고하였다. 이처럼 연구활동의 동기에 차이가 있다는 일 부의 주장이 있다 하더라도, 아동학 분야에서 우수한 연구역 량을 가진 중견연구자와 신진연구자의 연구활동이 활발하며 학문후속세대를 위한 지원사업의 선정 건수가 많은 것은 바람 직한 것으로 볼 수 있었다. 특히, 3 차년도와 4 차년도에 2 회 이 상 수혜한 17 명 연구자의 경우, 중견연구자 사업 3 명, 시간강 사나 신진연구자 대상 사업으로 중복 수혜한 연구자는 7명이 지만 신진연구자에서 중견연구자로, 시간강사에서 신진연구 자로, 학문후속세대에서 신진연구자로 지원사업을 달리하여 수혜한 연구자가 7명이라는 결과는 우수한 신진연구자들의 종단적 발전을 보여주는 예로 볼 수 있었다.

연구과제의 수행 현황으로, 소수의 연구과제가 중단된 것 으로 나타난 결과는 제시된 이유에 근거할 때 연구자의 지위 변동에 의한 사업 수행의 자격이 소멸되었기 때문으로 이해되 었다. 연구결과물로써 보고서의 제출은 연구과제 수행자의 의 무이다. 그러므로 아직 보고서 제출기간이 종료되지 않았을 경우를 제외한 소수의 연구과제에서 연구보고서가 미제출된 것으로 기록된 것은 데이터의 오류가 없는지 확인할 필요가 있을 것으로 생각되었다. $79.0 \%$ 의 연구과제가 1 년의 연구기 간으로 수혜를 받았다는 결과와 함께 연구과제 당 발표 논문 이 평균 2 편에 미치지 못하며, 저서의 출판 건수가 미미하다는 결과는 연구기간이 1 년인 과제 당 의무 발표 논문 또는 저서가 1 편이기 때문에 결과된 것으로 볼 수 있었다.

연구과제의 특성으로서 두 번째, 연구자의 특성을 분석한 결과, 책임연구자로서 평균 2.7 회, 공동연구자로서 평균 0.9 회
연구비 수혜 업적이 있고 학술논문 게재 편수는 평균 15.9편 으로, 피인용수는 평균 260.3으로 나타났다. 이러한 연구자의 연구비 수혜 업적 및 연구 업적은 3차년도와 4차년도에 그 이 전 보다 상대적으로 높아지고, 특히 연구 업적에서의 연구자 간 개인차가 큰 경향을 보였다. 연구자의 소속기관 소재지는 수도권 지역인 경우가 $54.3 \%$ 를 차지하여 비수도권 지역보다 높은 비율을 보였다. 국립대학을 제외한 수도권의 우수 사립 대학에 연구비 수혜나 연구비 규모가 편중된다고 알려져 왔다 (NRF, 2018a, 2018d). 이는 수도권에는 연구중심대학이, 지방 에는 교육중심대학이 많기 때문으로 해석되고 있다(Y.-S. Kim \& Jung, 2012; H.-S. Lee et al., 2011). 그러나 아동학 분야에서 는 1차년도 이후 점차 비수도권 대학 소속 연구자들의 수혜 비 율이 상대적으로 높아지는 경향을 보이는 것으로 나타나 지방 대학이 우수한 교원의 확보로 연구비의 수혜와 연구성과를 점 차 많이 내고 있다고 볼 수 있었다. 이상과 같은 연구자의 특성 변화는 사업 신청자격으로 최근 5년간 연구업적을 더 높게 요 구하고 우수한 사업성과를 낸 연구자를 우대함으로써 우수한 연구자의 유입을 유도하는 NRF (2018c)의 사업 방향에 따라 나타난 결과로 해석되었다. 구체적으로 조사기간 동안 2회 이 상 연구과제를 수혜한 연구자 25명과 1회 수혜한 연구자 72 명 간의 연구자 특성이 어떤 차이가 있는지 분석한 결과, 연구비 수혜 업적에서만 유의한 차이가 있으며, 학술지 게재 논문과 피인용수는 차이가 없는 것으로 나타났다. 연구의 양적 측면 에서의 논문 편수와 질적 측면에서의 피인용 횟수보다는 연구 책임자나 공동연구자로 연구과제를 수행한 역량이 중요하다 는 것을 보여주는 결과였다. 물론 연구과제의 참여자로 선정 되는 것과 연구활동의 질적 가치를 평가하는 척도인 논문 발 표량 및 피인용수(So, 2013)가 관계 있겠으나, 연구과제의 평 가에서 연구의 창의성 반영 비율이 높다는 것(NRF, 2018a)이 과제의 선정과 더 의미 있는 관계를 보였을 가능성이 있다고 도 생각되었다. 그러나 2004년부터 2017년까지 생활과학 분 야 연구자들의 평균 피인용 횟수가 6.4라는 점(KCI, 2018)을 고려할 때, 연구자간 피인용 횟수가 큰 편차를 보임에도 불구 하고 연구과제 수혜자는 피인용수가 높아 연구역량이 우수하 다고 인정할 수 있었다. 또한 일부 연구자는 학술논문 게재 편 수와 피인용 횟수가 매우 높아 뛰어난 연구역량을 가지고 있 음을 알 수 있었다. 이러한 본 연구의 결과를 통해 동일 학문분 야 연구자들의 연구동기가 자극받기를 기대해 보았다.

한편, 연구과제의 연구방법적 특성으로서 연구주제를 내용 분석한 결과, 전 조사기간 동안 변인간의 관계 분석과 프로그 램의 개발 및 효과 분석을 주제로 한 연구과제의 빈도가 높게 
나타났다. 3 차년도에 변인간 관계 분석 주제가 많이 증가한 것 은 2011년부터 시간강사 연구 지원사업이 시작되어 수혜 건 수가 늘어나면서 전 조사기간 다수를 차지해 왔던 이 주제의 연구 또한 증가한 것으로 해석되었다. 그리고 3차년도와 4차 년도에는 문헌자료나 제도의 분석, 저술·번역 등의 주제와 함 께 특히 도구 개발과 기타 개발 주제의 과제가 선정된 비율이 그 이전보다 상대적으로 높아진 것으로 나타나 주목되었다. 4 차년도의 경우, 사물인터넷의 활용, 앱 개발, 빅데이터의 분석 과 같은 연구방법 측면에서의 학문간 융합을 시도한 과제들을 예로 들 수 있었다. 이러한 결과는 연구주제의 창의성 요구가 높아지는 경향(NRF, 2018c)에 따른 것으로 볼 수 있었다. 아동 의 삶과 관련된 연구문제 자체를 사회문제의 해결이나 정책 으로 보는 응용연구가 확산되는 미국의 아동발달 연구 경향과 유사한 경향(Son, 2013)을 보이는 것으로 해석되었다. 또 아동 의 발달 관련 연구변인이 사회성 발달 관련 변인에 치우쳐 다 루어졌으나, 아동과 성인 간의 관계적 특성, 성인의 개인적 특 성 변인을 다룬 과제 건수가 상대적으로 많다는 것은 생태학 적 맥락에서 아동의 발달을 조망하는 아동학의 학문적 성격 (Belsky, Lerner, \& Spanier, 1984)에 맞는 연구주제가 선정된 것 으로 볼 수 있었다.

연구과제의 특징은 연구대상에서도 발견되었다. 유아 대상 의 연구과제가 2 차년도 이후 지속적으로 최다 연구대상으로 선정되어 유아기의 발달에 대한 연구자들의 관심이 높다고 볼 수 있었다. 나아가 특수 연구대상을 포함한 과제의 비율이 상 대적으로 감소하고는 있으나 전 조사기간 동안 전체 선정 건 수의 약 $35 \%$ 를 차지함으로써 연구의 창의성을 높게 평가 받 는데 기여했다고 짐작되었다. 다문화가정의 아동, 발달정신병 리를 가진 아동, 해외 한국 아동이나 다국가의 아동으로부터 CCTV영상데이터까지 다양한 연구대상을 포함한 연구과제 는 사회문제에 해결점과 시사점을 제공하는 응용학문으로서 의 아동학의 목적(Son, 2013)에 비추어 적절한 연구주제로 평 가되었기 때문에 선정될 수 있었다고 생각되었다. 다문화가정 의 아동은 2000 년대 후반부터 국내 다문화가정의 증가와 그 2 세대 어린 자녀의 적응 문제가 대두됨(Moon et al., 2010)에 따 라 2차년도부터 연구자들의 지속적인 관심 대상이 되기 시작 했고, 상대적으로 해외 한국 아동, 그리고 기존의 이혼 가정, 한부모 가정, 별거 가정, 조손 가정과 같은 특수 가족유형과 저 소득 가정환경에서의 아동에 대한 관심이 줄었을 것으로 추측 해 볼 수 있었다. 또 4차년도에 학대 아동에 대한 연구가 증가 한 것은 2015년 CCTV의 설치를 의무화한 영유아보육법 개정 안이 통과되면서 아동학대에 대한 사회적 관심이 높아진 것과
무관하지 않을 것으로 생각되었다. 이처럼 특수한 연구대상을 포함한 연구과제의 선정은 사회문화적·제도적 변화에 따라 영향을 받았을 것으로 추측할 수 있으나, 연구과제의 선정 시 연구의 창의성이 우선되므로 연도범주에 따른 각 특수 아동 대상의 과제 선정 건수를 연구대상자의 특성에 한정하여 비 교, 해석하는 데는 주의가 요구되었다.

또 다른 측면으로 연구과제의 방법적 특성을 살펴본 바, 3 차 년도와 4차년도에는 (단기)종단적 접근을 적용한 연구, 그리고 연구방법 유형으로서 조사연구와 실험연구가 다수를 차지한 가운데 양적연구 및 질적연구, 기존의 데이터를 활용한 연구 가 상대적으로 증가한 것을 알 수 있었다. 또한 통계분석방법 으로 차이검증이 많이 적용되었으나 같은 기간 경향분석 및 구 조방정식모형, 잠재성장모형·자기회귀교차지연모형·성장혼 합모형, 요인분석의 적용 빈도가 상대적으로 높아진 것으로 나 타났다. 서구에서는 혼합연구방법을 적용한 연구가 증가하며 (Johnson \& Onwuegbuzie, 2004), 유아발달 관련 응용연구에서 의 방법론적 발달이 연구의 경향 변화를 촉진한다(Foster, 2010) 고 주장된다. 본 연구에서 밝혀진 국내 연구과제에서의 이러한 변화는 연구비 지원사업이 연구의 경향 변화를 촉진하는 데 긍 정적인 기여를 하고 있음을 보여주었다. 특히 연구과제에 적용 된 방법적 측면에서의 분석을 통해, 대형 표본의 종단적인 발 달자료를 활용하여 변인간 인과관계 추론이 보다 더 가능한 변 화 분석(change analysis)을 시도하는 연구로의 변화 경향(Son, 2013)이 연구과제 선정에 잘 반영되고 있음을 알 수 있었다.

이상에서 밝혀진 연구비 수혜과제의 특성 분석에 기초하여 추후 연구비 지원자들을 위한 제언을 하면 다음과 같다. 첫째, 연구비 지원사업별 수혜과제의 선정 경쟁률은 연구분야별 지 원자 수에 따라 차이가 있겠으나, NRF의 사업계획에 따라 크 게 좌우된다고 볼 수 있다. 실제로 NRF (2018c)에서는 연구자 의 성장단계별로 연구가 가능하도록 지원하겠다는 사업 추진 방향을 밝힌 바 있어, 앞으로도 아동학 분야 연구자들의 학문 후속세대 지원사업, 신진연구자 지원사업의 수혜 가능성이 높 아질 것으로 예상되었다. 매년 발표되는 사업안내를 참고하여 세부적인 준비가 가능할 것이다. 둘째, 선정된 연구과제의 연 구자 특성에 비추어, 최근 연구자의 개인 연구역량에 대한 요 구가 높아지고 있음을 알 수 있었다. 공동 연구과제에의 참여 를 통해 과제 수행 경험을 늘리고, 영향력 있는 질 높은 논문 편수를 축적해 나가는 다방면의 철저한 준비가 필요할 것이 다. 셋째, 연구주제의 창의성에 대한 기대가 높아지는 가운데 (NRF, 2018c), 특히 특수 연구대상을 포함한 연구와 같은 생태 학적 맥락에서 사회문제의 해결과 시사점을 제공하는 응용연 
구에 주목할 필요가 있을 것이다. 더불어, 연구과제의 연구방 법 측면에서는 혼합연구방법의 적용, 종단적 발달 자료를 활 용한 변화 분석에 초점을 둔 연구의 선정 건수가 증가하고 있 다는 것을 기억할 필요가 있다.

본 연구에서 아동학 분야의 범위는 NRF가 하위 5 가지 연 구분야에 한정하여 제시한 것이었다. 그러나 아동복지체계나 아동권리 등의 분야 연구도 아동학회지에 게재될 수 있으므로 (KACS, 2018) 추가적인 세부 연구분야를 포함한다면 연구비 지원 가능 기관과 분석대상 수혜 과제의 폭은 달라질 수 있을 것이다. 또한, 본 연구는 객관적인 연구비 지원 실적을 일일이 확인하지 않은 상태에서 연구비 지원 가능 기관을 선정함으 로써 선정 범위나 기준에 대한 이견을 야기할 수 있고, 2004년 부터의 데이터에 근거하여 제시된 연구자의 업적 자료 $(\mathrm{KCI}$, 2018)에 근거하여 분석하였다는 점에서 연구결과의 해석에 주의가 필요할 것이다.

그럼에도 불구하고 아동학 분야의 연구자들이 연구비의 지 원 신청을 통해 연구의 생산성과 연구역량을 높일 수 있도록 연구비 지원기관 현황과 연구비 수혜 과제의 특성에 관한 정 보를 제공하였다는 데 연구의 의의를 두었다. 본 연구를 통해 연구비 지원사업에 대한 아동학 연구자들의 관심이 더욱 높아 지기를 기대해 본다.

\section{Notes}

This article was presented at the 2018 Annual Fall Conference of the Korean Association of Child Studies, Seoul, Korea.

\section{Conflict of Interest}

No potential conflict of interest relevant to this article was reported.

\section{References}

\section{In English}

Aithal, P. S. (2016). How to increase research productivity in higher educational institutions?: SIMS model. International Journal of Scientific Research and Modern Education, 1(1),
447-458. Retrieved from https://mpra.ub.uni-muenchen. de/71750/

Belsky, J., Lerner, R. M., \& Spanier, G. B. (1984). The child in the family. Reading, MA: Addison-Wesley Longman.

Bolli, T., \& Somogyi, F. (2011). Do competitively acquired funds induce universities to increase productivity? Research Policy, 40(1), 136-147. doi:10.1016/j.respol.2010.10.001

Brew, A., Boud, D., Namgung, S. U., Lucas, L., \& Crawford, K. (2016). Research productivity and academics conceptions of research. Higher Education, 71(5), 681-697. doi:10.1007/ s10734-015-9930-6

Chen, Z., Gong, C., Lin, L., Xu, S., Zhang, M., \& Zhou, X. (2015). Assessing junior faculty research productivity in th IS field: Recommendations for promotion and tenure standards for asian schools. Communications of the Association for Information Systems, 36(19), 357-368. doi:10.17705/1CAIS.03619

Crossref. (2018). Funder registry. Retrieved from https://www. crossref.org/services/funder-registry/

Foster, E. M. (2010). Causal inference and developmental psychology. Developmental Psychology, 46(6), 1454-1480. doi: $10.1037 / \mathrm{a} 0020204$

GeoNames. (2018). South Korea. Retrieved from http://www. geonames.org/1835841/south-korea.html

Hardre, P. L., Beesley, A. D., Miller, R. L., \& Pace, T. M. (2011). Faculty motivation to do research: Across disciplines in research-extensive universities. Journal of the Professoriate, 5(1), 35-69. Retrieved from https://www.missouristate. edu/assets/longrangeplan/Faculty_Motivation_to_Do_ Research.pdf

Harle, C. A., Vest, J. R., \& Menachemi, N. (2016). Using bibliometric big data to analyze faculty research productivity in health policy and management. Journal of Health Administration Education, 33(2), 285-293. Retrieved from https://scholarworks.iupui.edu/bitstream/ handle/1805/17166/Harle_2018_using.pdf?sequence $=1$

Hollister, C. V., \& Schroeder, R. (2015). The impact of library support on education faculty research productivity: An exploratory study. Behavioral \& Social Sciences Librarian, 34(3), 97-115. doi:10.1080/01639269.2015.1062584

Johnson, R. B., \& Onwuegbuzie, A. J. (2004). Mixed methods research: A research paradigm whose time has come. Educational Researcher, 33(7), 14-26. doi:10.3102/ 0013189x033007014

Meddings, K. (2013). FundRef: Connecting research funding to published outcomes. Insights, 26(3), 272-276. doi:10.1629/ 2048-7754.98

\section{In Korean}

Elsevier Korea. (2015). Research performance analysis. Research 
Trends and Performance, 7, 4-12. Retrieved June 10, 2018, from http://korea.elsevier.com

Han, D.-S., Jang, D.-H., Han, S.-H., \& Yang, J.-M. (2008). An empirical study on the impacts of public funding on the research performance of academic faculties. Korean Public Administration Review, 42(4), 265-290.

Huh, S. (2014). Application of new information technologies to scholarly journals: ORCID, CrossMark, and FundRef. Journal of the Korean Medical Association, 57(5), 455-462. doi:10.5124/jkma.2014.57.5.455

Jang, D. (2011). Jeongbuui yeongubi jiwon-i yeongujaui yeongusaengsanseong-e michin hyogwa bunseog [정부의 연 구비 지원이 연구자의 연구생산성에 미친 효과 분석] (Report No. NRF-2010-327-B00742). Retrieved from KRM website: https://www.krm.or.kr

Kim, M.-K. (2015). Analysis of Korean funder names and their variants in the FundRef registry (Master's thesis). Retrieved from http://www.riss.kr/link?id=T13703413

Kim, Y.-S., \& Jung, J.-S. (2012). Estimation of research cost based on research productivity of academic department. Korean Journal of Educational Administration, 30(4), 535-563.

Korean Association of Child Studies. (2018). Aims and scope. Retrieved from http://childstudies.org/about/

Korea Citation Index. (2018). Citation information of researchers. Retrieved from https://www.kci.go.kr/kciportal/po/ citationindex/poCretSear.kci

Lee, C. (2010). An empirical study on the impacts of public funding on the performance of researcher (Doctoral dissertation). Retrieved from http://www.riss.kr/link?id=T11958054

Lee, H.-S., Sim, C.-S., Hwang, D.-H., Lee, W.-Y., Lee, H.-J., Lee, Y.-B., . . Shin, H.-W. (2011). Study on resolution of barriers in the field of university research. Journal of Natural Sciences of Soonchunhyang University, 17(1), 39-48.

Moon, H. J., Kim, J. E., Yang, S. E., Lee, E. J., Chun, H. Y., \& Hwang, O. K. (2010). Social work with families. Seoul: Changjisa.

National Research Foundation of Korea. (2018a). Analyzing report of 2017 survey of research activities in universities (including 2005 2016). Retrieved from https://www.nrf.re.kr/cms/ board/general/view?menu_no $=318 \&$ nts_no $=101980$
National Research Foundation of Korea. (2018b). About $N R F$. Retrieved from https://www.nrf.re. $\mathrm{kr} / \mathrm{cms} /$ page/ main?menu_no=99

National Research Foundation of Korea. (2018c). Program classification. Retrieved from https://www.nrf.re.kr/biz/ main/total?biz_no=82

National Research Foundation of Korea. (2018d). Highlights on the 2018 survey of research activities in universities (NRF R \& D Brief 2018-44). Retrieved from https://www.nrf.re.kr/cms/ board/general/view?nts_no $=1084498$ menu_no $=317 \&$ nts_ no $=\&$ search_type $=\&$ search_keyword $=\&$ page $=$

Shin, J. C., Kim, H. H., Park, H. Y., \& Shim, H. K. (2009). Analysis on the factors of budget allocation to universities: Evaluation-based funding mechanism. The Journal of Economics and Finance of Education, 18(4), 59-87.

So, M. (2013). A study on the factors of affecting citation of articles in science and technology (Doctoral dissertation). Retrieved from http://www.riss.kr/link?id=T13247596

Son, S. H. (2013). Improving lives of children through applied interdisciplinary perspectives: Trends in early childhood development and learning research. Presented at the 2013 Annual Fall Conference of the Korean Association of Child Studies, Seoul, Korea.

Woo, Y.-H., \& Hong, M.-Y. (2017). Effects of environment and individual characteristics on research productivity: An empirical analysis of Korean public administration researchers. The Korean Journal of Local Government Studies, 21(2), 435-460. doi:10.20484/klog.21.2.18

\section{ORCID}

Hui Young Chun https://orcid.org/0000-0002-0152-3247

Received October 31, 2018 Revision received November 28, 2018 Accepted December 3, 2018 


\section{Appendix 1}

Examples of Funding Projects by Research Topic and Research Period

\begin{tabular}{|c|c|c|}
\hline Topics & Research period & Examples \\
\hline \multirow[t]{4}{*}{$\begin{array}{l}\text { Relational } \\
\text { analysis } \\
\text { among } \\
\text { variables }\end{array}$} & $2000 \sim 2004$ & $\begin{array}{l}\text { - The effects of maternal parenting behaviors, children's social information processing, daily hassles, } \\
\text { and emotion regulation on children's aggression: A structural equation modeling analysis } \\
\text { - Children's adaptation and behavior problems according to their rearing environment: Korean } \\
\text { adoptees in the U.S., institutionalized and home-reared children in Korea }\end{array}$ \\
\hline & $2005 \sim 2009$ & $\begin{array}{l}\text { - Acculturation stress, place attachment, and mental health among Korean youth in the United States } \\
\text { - The relationship between proverb comprehension in context and children's cognitive development } \\
\text { during the concrete stage }\end{array}$ \\
\hline & $2010 \sim 2014$ & $\begin{array}{l}\text { - A survey study on the characteristics of peer relations and their development across higher grades in } \\
\text { an elementary school } \\
\text { - Resilience against neighborhood risk among adolescents }\end{array}$ \\
\hline & $2015 \sim$ July 2018 & $\begin{array}{l}\text { - A short-term study on adaptation trace type and predictors of childcare centers for infants only } \\
\text { - The effects of grit on turnover among child care teachers }\end{array}$ \\
\hline \multirow[t]{4}{*}{$\begin{array}{l}\text { Program } \\
\text { development } \\
\text { and its effect }\end{array}$} & $2000 \sim 2004$ & $\begin{array}{l}\text { - Development of mother-child interaction program to enhance psychological adjustment of children } \\
\text { of North Korean defectors } \\
\text { - Effects of script training on low- and middle-income preschoolers' script knowledge and topic } \\
\text { performance skill }\end{array}$ \\
\hline & $2005 \sim 2009$ & $\begin{array}{l}\text { - The effect of group art therapy on self-esteem and sociality of children of international marriage } \\
\text { immigrants (Onnuurian) } \\
\text { - A study on play therapy for abused children }\end{array}$ \\
\hline & $2010 \sim 2014$ & $\begin{array}{l}\text { - Relationships between verbalization through decomposing-connecting object representation and } \\
\text { representational redescription process in children's drawing behavior } \\
\text { - A longitudinal intervention study to prevent behavior problems among school-aged children and } \\
\text { adolescents }\end{array}$ \\
\hline & $2015 \sim$ July 2018 & $\begin{array}{l}\text { - Effectiveness of parent-child relationship support program through improvement of anger control } \\
\text { ability of mothers of young children: Integrated approach by CPRT and AL } \\
\text { - The effectiveness of parent-child interaction therapy for neglected or abused children and their } \\
\text { offender parents }\end{array}$ \\
\hline \multirow{4}{*}{$\begin{array}{l}\text { Instrument } \\
\text { development }\end{array}$} & $2000 \sim 2004$ & - Standardization of Korean Bayley Scales of infant development: Pilot studies \\
\hline & $2005 \sim 2009$ & $\begin{array}{l}\text { - The School Readiness Inventory for kindergarteners: Development and validation } \\
\text { - A comparative cultural study on the emotional response tendency of children }\end{array}$ \\
\hline & $2010 \sim 2014$ & $\begin{array}{l}\text { - The development and validation of a scale to measure the mathematical interaction of young } \\
\text { children's parents } \\
\text { - Development and validation study of the Korean version of Rothbart's temperament scale: Focusing } \\
\text { on effortful control }\end{array}$ \\
\hline & $2015 \sim$ July 2018 & $\begin{array}{l}\text { - Construction and validation of the Maternal Emotion Coaching Questionnaire } \\
\text { - The development of a child care adaptation scale for infants and toddlers }\end{array}$ \\
\hline \multirow[t]{4}{*}{$\begin{array}{l}\text { Development } \\
\text { of other } \\
\text { subject-matter }\end{array}$} & $2000 \sim 2004$ & $\begin{array}{l}\text { - A study on utilizing family child care services for infant care in Korea } \\
\text { - Development of a comprehensive integrated child care services model for children with and without } \\
\text { disabilities }\end{array}$ \\
\hline & $2005 \sim 2009$ & None \\
\hline & $2010 \sim 2014$ & $\begin{array}{l}\text { - An analysis on policies and exchange programs for the development of youth competency and social } \\
\text { cohesion in the EU }\end{array}$ \\
\hline & 2015 July 2018 & $\begin{array}{l}\text { - Development of child care support models of health and safety for young children using IoT in } \\
\text { childcare centers } \\
\text { - The development of a mobile learning system for Korean language education of preschoolers in } \\
\text { multicultural families }\end{array}$ \\
\hline \multirow[t]{4}{*}{$\begin{array}{l}\text { Literature. } \\
\text { system analysis }\end{array}$} & $2000 \sim 2004$ & $\begin{array}{l}\text { - Outlooks on Korean children before liberation: } 1876-1945 \\
\text { - A study on the child care system in Sweden }\end{array}$ \\
\hline & $2005 \sim 2009$ & None \\
\hline & $2010-2014$ & None \\
\hline & 2015-July 2018 & $\begin{array}{l}\text { - An analysis of the 'morality' in picture books in the teachers' guidance manual for the Nuri } \\
\text { curriculum for 3-5-year-old children in Korea } \\
\text { - Preliminary study on utilization of image big data from CCTVs at child care centers }\end{array}$ \\
\hline \multirow{4}{*}{$\begin{array}{l}\text { Writing. } \\
\text { translation }\end{array}$} & $2000-2004$ & None \\
\hline & $2005 \sim 2009$ & None \\
\hline & $2010 \sim 2014$ & $\begin{array}{l}\text { - Psychopathology and family: Developmental psychopathology approach to child and youth } \\
\text { psychopathology } \\
\text { - The cultural nature of human development }\end{array}$ \\
\hline & $2015 \sim$ July 2018 & None \\
\hline
\end{tabular}

